\title{
ENVIRONMENTAL IMPACTS OF AGRICULTURAL PRACTICES IN KINTA DISTRICT (AGBANGNIZOUN COMMUNE)
}

\author{
Louis Dedegbe AHOMADIKPOHOU \\ Laboratory of Rural Geography and Agricultural Expertise (LaGREA) \\ Faculty of Humanities and Social Sciences (FASHS) / University of Abomey - Calavi \\ https://doi.org/10.35410/IJAEB.2022.5708
}

\begin{abstract}
The technical cultural and the rudimentary means of production contribute to deterioration of soils in the precinct of Kinta. The present research is to contribute to a better knowledge environmental impact for agricultural practices in the precinct in Kinta.

The methodological approach used articulates around the collection the data, the treatment of data and the analysis results with the help PEIR model. To the total, 90 peasants have been interrogated.

The results of this research show the peasants $(50 \%)$ put some agricultural systems in place as the practice deep ploughing, the fires of vegetation and the use agricultural inputs to increase the agricultural production. $90 \%$ these practices constitute the real factors deterioration environment. Facing this situation, $80 \%$ of peasants develop strategies improvement agricultural practices for protection and the safeguard environment.
\end{abstract}

Keywords: Kinta; deterioration of environment.

\section{INTRODUCTION}

Africa is facing significant degradation of its natural resources as $80 \%$ of Africa's population is rural and directly dependent on natural resources as a means of subsistence (M. Boko and E. Ogouwalé, 2007, p. 25).

In Benin, agriculture encounters difficulties, most of which come from nature but also from anthropogenic action (G. Hennou, 2000, p. 17). Indeed, the territory is subject to water constraints that affect the distribution of seasons. The various harmful impacts on the environment of certain intensive production practices are no longer to be demonstrated both in terms of the nuisances generated (air, water and soil pollution) and the loss of biodiversity at the different levels of organization of life (population, community, landscape) or the sanitary quality of production (J. Dansi, 2007, p. 21). That is, the regression of vegetation cover, soil erosion and chemical pollution, pollution of rivers and bodies of water and air pollution (N. Djanan, 2000, p. 45).

The expansionist crop strategy endangers agricultural soils and pastoral areas (Y. Djaouga, 2003, p. 9). The need to produce more and more often forces the peasant to adopt methods that deplete the earth, at the risk of mortgaging the natural environment for future generations (J. Assouni, 2004, p. 26). 
However, efforts still need to be made to identify the existing correlations between agriculture and environmental components in order to contribute to the sustainable development of the Kinta Borough because, any sustainable development in need of a healthy environment stipulates (M. Boko, 2002, p. 8). This is why the time is no longer for repetitive remuneration of the causes and phenomena responsible for the collapse of ecosystems, but rather for the search for and implementation of concrete solutions to stop this scourge, which increasingly threatens the monitoring of all humanity (R. Chris, 2006, p. 74). This research focused on studying the environmental impacts related to agricultural practices in kinta District (Agbangnizoun Commune).

The Arrondissement of Kinta is located in the Zou Department in southern Benin and is one of the ten (10) arrondissements of the Commune of Agbangnizoun according to the latest territorial division. It is located between $7^{\circ} 02^{\prime}$ and $7^{\circ} 05^{\prime}$ north latitude and between $1^{\circ} 59^{\prime}$ and $2^{\circ} 02$ east longitude. It has five (05) villages as shown in Figure 1.

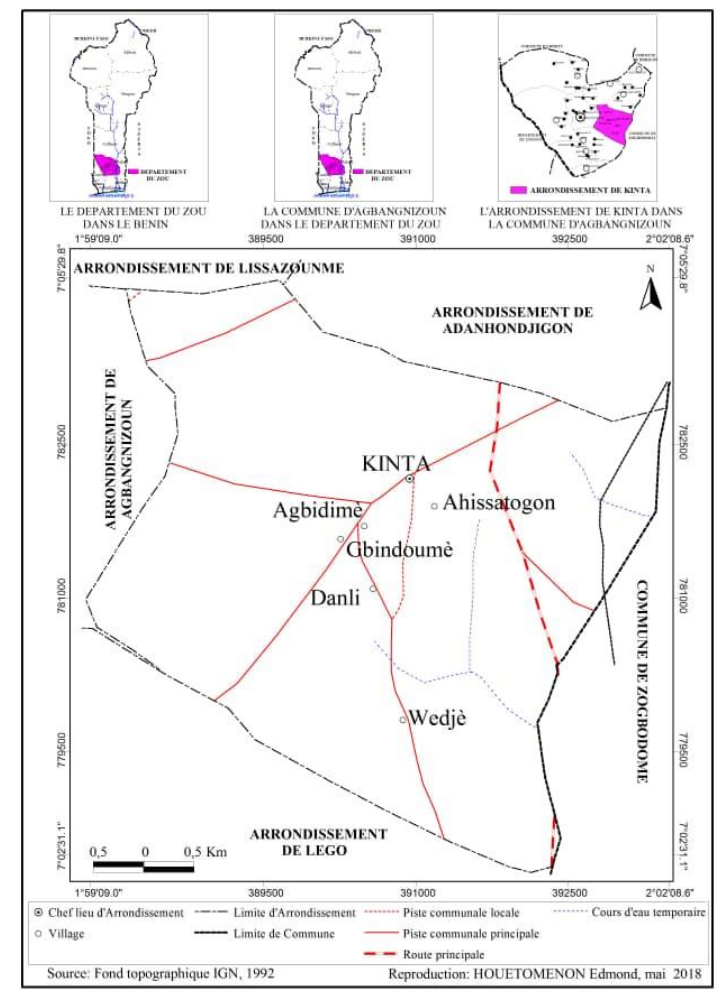

Figure 1: Geographical and administrative locations of the Borough of Kinta

The analysis of Figure 1 shows that the Arrondissement of Kinta is bounded to the north by the Arrondissement of Lissazounmè and to the north-east by the Arrondissement of Adanhondjigon, to the east by the Commune of Zogbodomey, to the south by the Arrondissement of Lègo and to the west by the Arrondissement of Agbangnizoun.

\section{MATERIALS AND METHODS}

As part of this research, the methodological approach adopted involves the collection of data, their processing and the analysis of the results obtained. The data used during this research 
Vol. 07, No. 01; 2022

ISSN: $2456-8643$

consist of: topographical backgrounds of the IGN (1992), climatic (Météo-Bénin), soil (LSSE), demographic (INSTaD), agricultural (MAEP) data.

To collect data in the field, the techniques and tools used mainly concern direct observation using a grid, individual interview and focus group discussion on the basis of questionnaires and interview guides. The sample size was determined by the probabilistic method of D. Schwartz (1995). It was calculated with a confidence level of $95 \%$ and a margin of error of plus or minus $5 \%$. The formula is as follows: $\mathrm{N}=\mathrm{Z} \alpha 2 . \mathrm{P} \mathrm{Q}^{/ \mathrm{d} 2}$ with $\mathrm{N}=$ rounding sample size $\mathrm{Z} \alpha=$ fixed deviation at 1.96 corresponds to a confidence level of $95 \%$.

$\mathrm{P}=$ number of households in the district / number of households in the commune, $\mathrm{Q}=1-\mathrm{P} ; \mathrm{d}=$ margin of error which is equal to $5 \%$. The choice of respondents meets the following criteria:

- be the head of an agricultural household with fields on the farm or working in departments dealing with agricultural matters;

- have at least twenty-five (25) years in order to better inform about the agricultural production systems developed in the district;

- reside in the borough for the last five (05) years, this criterion is retained because to talk about the realities of an environment, you must have lived there for a certain number of years. A total of 90 farmers were interviewed given the importance of agricultural activities and especially the state of environmental degradation. Outside agricultural households, several resource persons were interviewed. These are the village chiefs of the localities surveyed and the members of the associations of producers of different cultures (Zea mays, Manihot esculenta, Oriza glaberrima, Capsicum annum, Hibiscus esculentus, etc.). Thus, 15 resource persons were interviewed to complete the sample of households surveyed.

The data collected in the field was analyzed and processed with SPSS for Windows software. The Excel spreadsheet was used to produce the tables and graphs. ArcView 3.2 software has been used to reproduce maps. The Leopold matrix (1971) was used for the identification, assessment of environmental impacts.

\section{RESULTS}

3.1. Biophysical Foundations of the Impacts of Agricultural Practices in the Borough of Kinta

\subsubsection{Topographic and climatic characteristics}

Topographically, the district of Kinta offers a relief of barre earth belonging to the geomorphological ensemble of the Abomey plateau. It has the land formed on the geological substratum called the Continental terminal (S. Adam and M. Boko, 1993, p. 12). These soils are fairly homogeneous, sandy-loamy, not very profonds with rapid leaching (Figure 2). 
Vol. 07, No. 01; 2022

ISSN: $2456-8643$

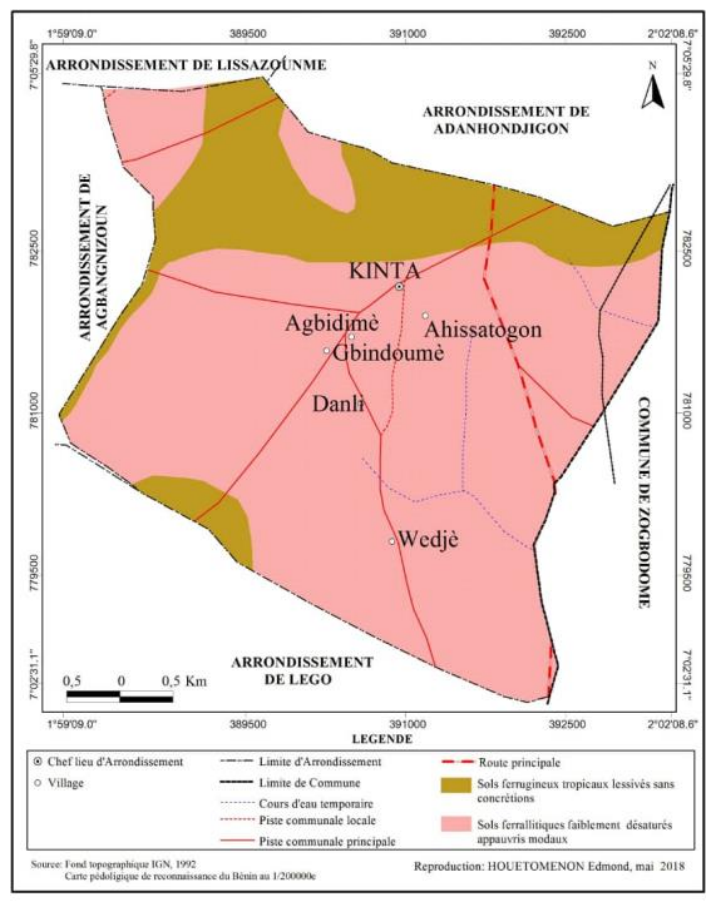

Figure 2: Soil formations in the Borough of Kinta

The analysis in Figure 2 shows that the land use rate varies between $43-56 \%$ depending on the soil type. Land constraints, due to the unequal distribution of land, are an obstacle to any development initiative for intensive exploitation. Women have no control over land and do not inherit it according to customary law Cultivation practices vary from one peasant to another and apply according to means, types of soil and availability of labour and arable land.

The climate of the study area is of the Sudano-Guinean or subequatorial type with two rainy seasons alternating by two dry seasons. The rainfall generally recorded in the area varies between $800 \mathrm{~mm}$ and $1,400 \mathrm{~mm}$. Relative humidity is $55 \%$ to $95 \%$ with an average temperature of $25.3^{\circ} \mathrm{C}$ to $29.7^{\circ} \mathrm{C}$ (S. Adam and M. Boko, 1993, p. 17). Plot 3 shows the climate diagram for the Borough of Kinta.

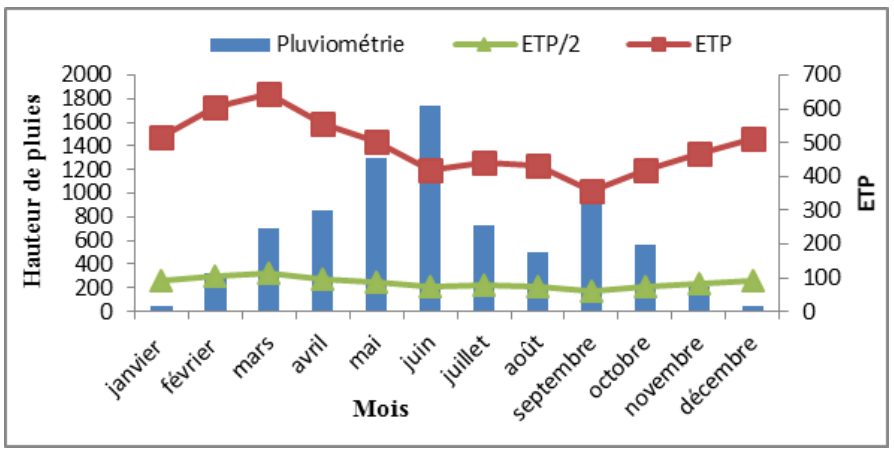

Figure 3 : Kinta Borough Climate Diagram from 1986 to 2016

Source : Météo-Bénin, 2018 
The analysis of Figure 3 shows that this climate is characterized by two rainy seasons (a large season from mid-March to mid-July and a small season from mid-September to mid-November) and two dry seasons (a large season from mid-November to mid-March and a small season from mid-July to mid-October). The months of May and June recorded the highest rainfall $(156.7 \mathrm{~mm}$ and $203.9 \mathrm{~mm}$ ). The lowest rainfall heights are recorded in the months of December and January. This leads to increased water needs, dehydration and diseases such as measles and itching.

\subsubsection{Typology of cultural practices}

In the Borough of Kinta, cultivation practices are characterized by monoculture, crop association and crop rotation.

\section{* Monoculture}

This practice characterized by a single crop on the plot is essentially dominated by: Zea mays, Manihot esculenta and Arachis hypogea. The monoculture of Zea mays and Arachis hypogea is practiced during the two agricultural seasons (plate 1).
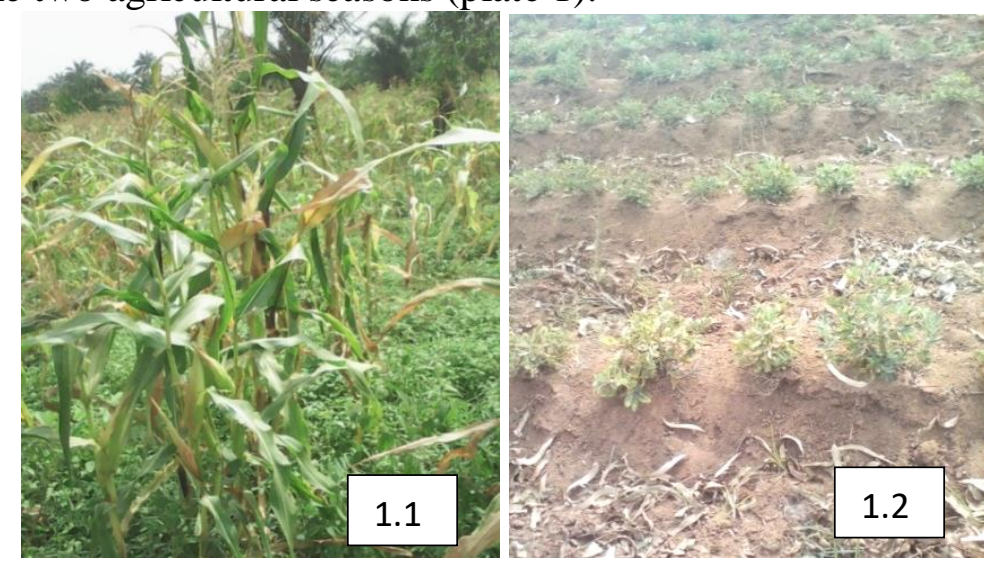

Plate 1: Monoculture of Zea mays and Arachis hypogea in Danli

Shooting: Houétomènon, June 2018

From the observation of plate 1, photo (1.1) shows the maize crop and photo (1.2) shows groundnut cultivation in Danli. According to $92 \%$ of respondents, these crops are more cultivated in the Kinta borough.

\section{* Cultural Association}

In the Borough of Kinta, two to four crops are produced in the same field. According to the investigations, $88 \%$ of agricultural workers practice the cultural association (photo 1). 


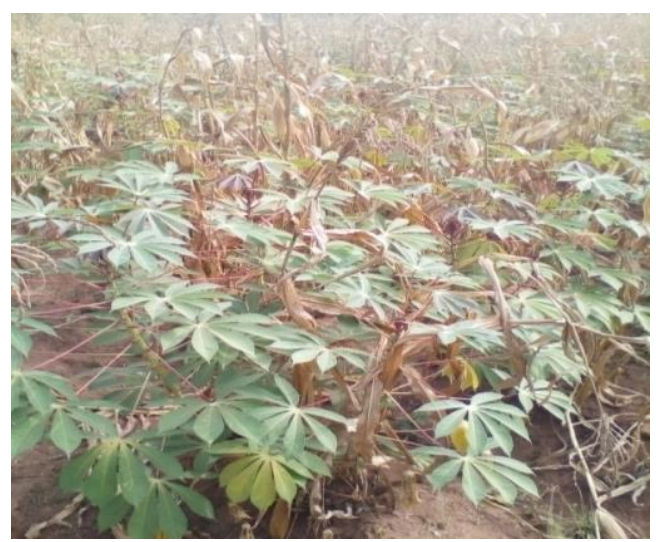

Photo 1: Association of Zea mays and Manihot esculenta in Wêdjè

Shooting: Houétomènon, June 2018

The observation of photo 1 shows the association of Zea mays and Manihot esculenta in Wêdjè. According to $89 \%$ of the surveys, the association of these two cultures is more practiced in the study area.

\section{* Crop rotation}

Crop rotation allows an establishment of order of succession of crops on the same plot. This cultivation practice is used by $54 \%$ of the farmers surveyed. Table I shows the types of rotations performed and their patterns.

Table I : Type of rotations and their patterns

\begin{tabular}{|l|l|l|}
\hline Villages & Types of rotation & Motifs \\
\hline Wèdjè & $\begin{array}{l}\text { Zea mays ; Lycopersicum esculentum ; } \\
\text { Manihot esculenta; Capsicum annum }\end{array}$ & Good crop yield \\
\hline Ahissatogon & $\begin{array}{l}\text { Capsicum annum; Hibiscus esculentus ; Zea } \\
\text { mays }\end{array}$ & $\begin{array}{l}\text { Back positive effect of } \\
\text { fertilizers, corn and dead } \\
\text { leaves }\end{array}$ \\
\hline Danli & Dioscorea alata; Ipomea potatoes & Beneficial resting field \\
\hline
\end{tabular}

Source : Field surveys, July 2018

An examination of Table I shows that this technique allows $60 \%$ (farmers) to have a yield because the residues of dead plants are used as fertilizer for the next season.

\section{Itinerant slash-and-burn cultivation}

Itinerant slash-and-burn cultivation is the main technique for clearing. In Kinta, 98\% of farmers have adopted this technique for soil preparation (photo 2). 


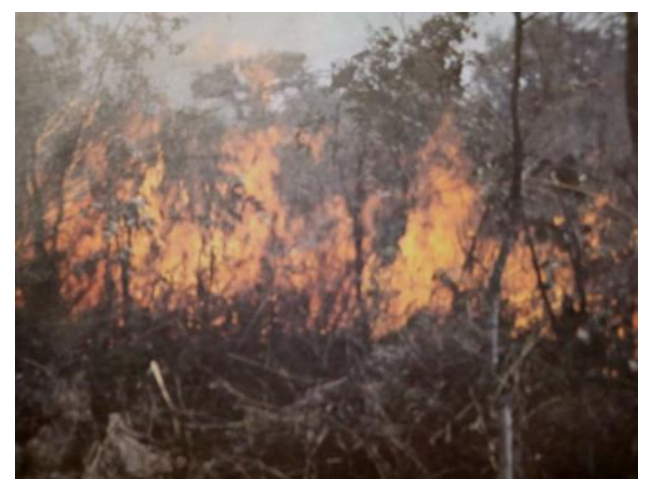

Photo 2: Itinerant slash-and-burn cultivation in Ahissatogon

Shooting: Houétomènon, June 2018

Photo 2 shows the itinerant slash-and-burn culture in Ahissatogon. This soil preparation is made of clearing with incineration when it comes to new land left fallow.

\subsubsection{Traditional cultivation tools and techniques}

The tools and especially the techniques used by farmers in the study area pose a serious threat to the environment.

\subsubsection{Traditional tools}

The tools used in Kinta's Rounding are rudimentary (plate 2).

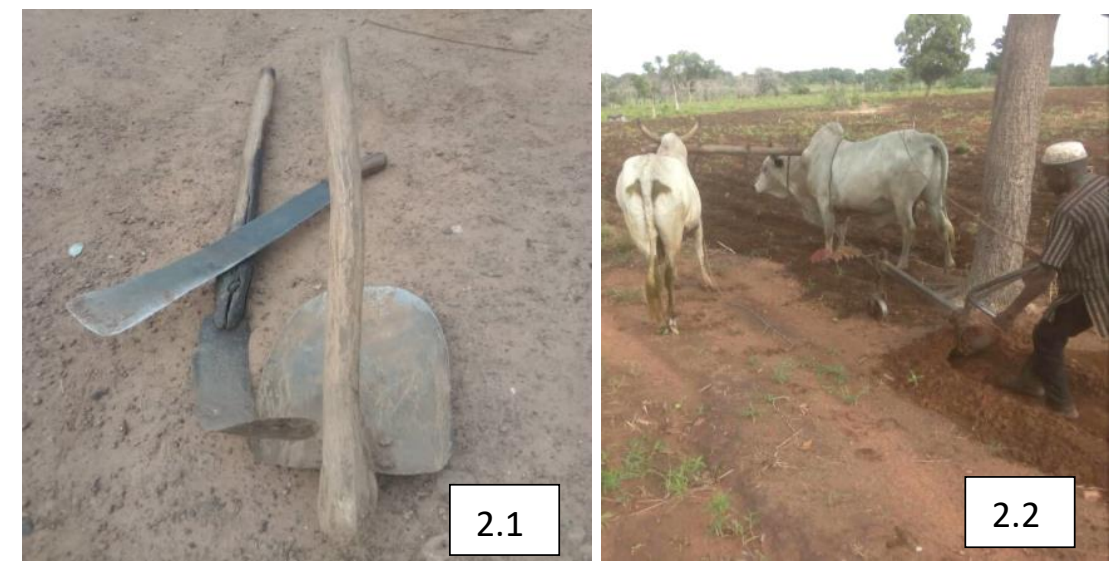

Plate 2: Traditional production tools in Kinta

Shooting: Houétomènon, June 2018

The observation of plate 2 shows that the peasants (80\%) continue to practice agriculture with tools such as hoe, cutter, axe (2.1) and plough with two oxen (2.2). indeed, the use of modern work tools is not yet a total reality in the Borough of Kinta.

\subsubsection{Modern tools}

The mechanization of agriculture, which is at its beginning, is practiced in the District of Kinta but on a small scale. This is due to the costs of these tools and the small size of farms. They boil down to the use of machinery (photo 3) and agricultural inputs (chemical fertilizers and phytosanitary products). 


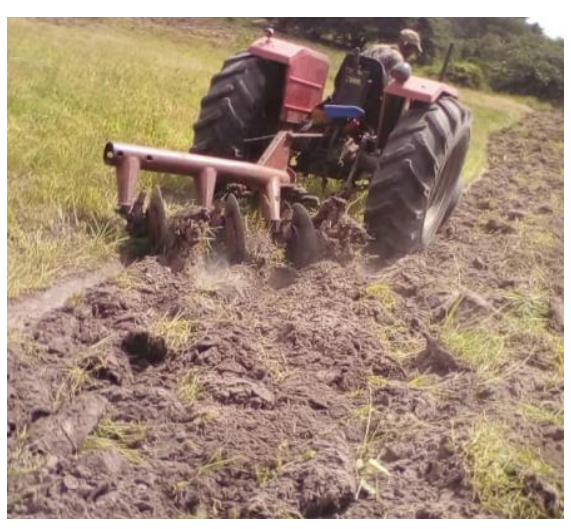

Photo 3: Modern agricultural tool in Danli

Shooting: Houétomènon, June 2018

The observation in photo 3 shows a tractor in Danli, a tool that is mainly used by agricultural research centers such as the SDA/Agbangnizoun and some groups of agricultural producers according to field work.

\subsubsection{Improved crop technique}

The technique of improved crops is practiced by less than $5 \%$ of the farmers surveyed in the Kinta District. This technique offers several advantages (Table II).

Table II : Comparison of time according to the means used

\begin{tabular}{|l|lcc|lc|}
\hline $\begin{array}{l}\text { Agricultural } \\
\text { Operations }\end{array}$ & $\begin{array}{l}\text { Working time with tractor } \\
\text { (day/ha) }\end{array}$ & $\begin{array}{l}\text { Manual working time } \\
\text { (day/ha) }\end{array}$ & \\
\hline Billonnage & 1 & & 18 & \\
\hline Weeding & 0,5 & & & 6 & \\
\hline
\end{tabular}

Source : Field survey, July 2018

The estimates in Table II show that working with tractors is faster and requires less physical energy to develop large areas of fields. The billonnage of one hectare of field is done by the tractor in one (1) day against eighteen (18) days of manual work per agricultural worker. But the development of such mechanization of agriculture has adverse effects on the environmental components. Indeed, this mechanization causes soil compaction and rapid destruction by the soil nutrient stirring system (earthworm, etc.). The land ploughed in this way suffers a loss of humus.

Apart from tractors, farmers use chemical fertilizers and phytosanitary products as shown in Photo 4. 


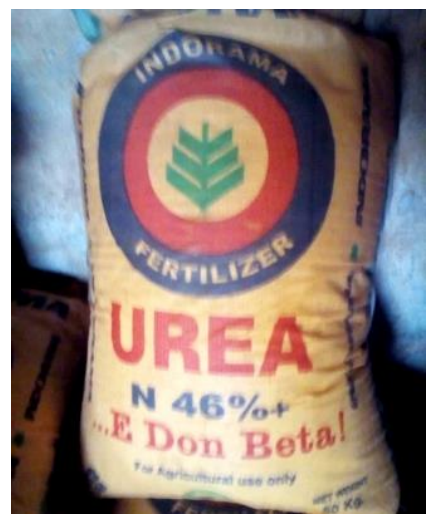

Photo 4: Production inputs in Ahissatogon

Shooting: Houétomènon, June 2018

In the Kinta District, chemical fertilizers such as NPK (Nitrogen, Phosphorus Potassium) and urea are used to increase agricultural yields; $90 \%$ of the farmers surveyed use mineral fertilizers for maize (Zea mays) and cowpea (Vigna unguiculata)

\subsection{Evolution of agricultural plantings and yields}

The main crops produced in the Kinta District are: Zea mays (maize), leafy vegetables, Arachis hypogea (groundnut), Vigna unguiculata (cowpea), Ipomea batatas (sweet potato), Dioscorea alata (yam), Lycopersicum esculentum (tomato) and Capsicum annum (chili), etc. Figure 4 shows the evolution of planting and production of zea mays culture between 2002 and 2016.

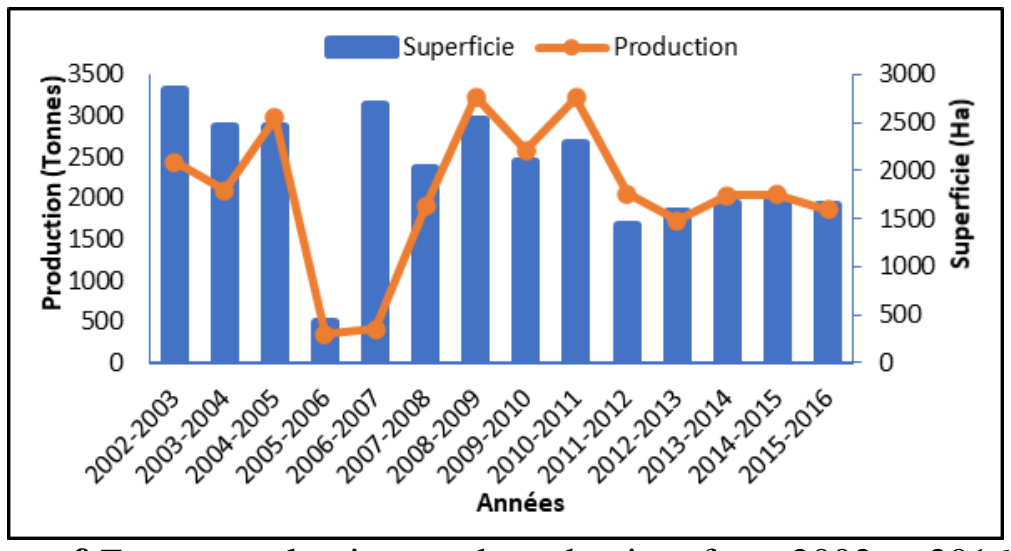

Figure 4: Evolution of Zea mays plantings and production from 2002 to 2016 Source : ATDA/Agbangnizoun

Figure 4 shows that from 2002 to 2005 , production was still below the area sown. This situation reflects the low yield recorded in Zea mays during these years and this decrease can be explained by the state of the soils due to the nature of the cropping systems developed in this district. From 2005 to 2006, production evolved according to the area sown. From 2009 to 2016, production is above the area sown.

Figure 5 shows the evolution of Lycopersicum esculentum plantings and production between 2002 and 2016. 
Vol. 07, No. 01; 2022

ISSN: $2456-8643$

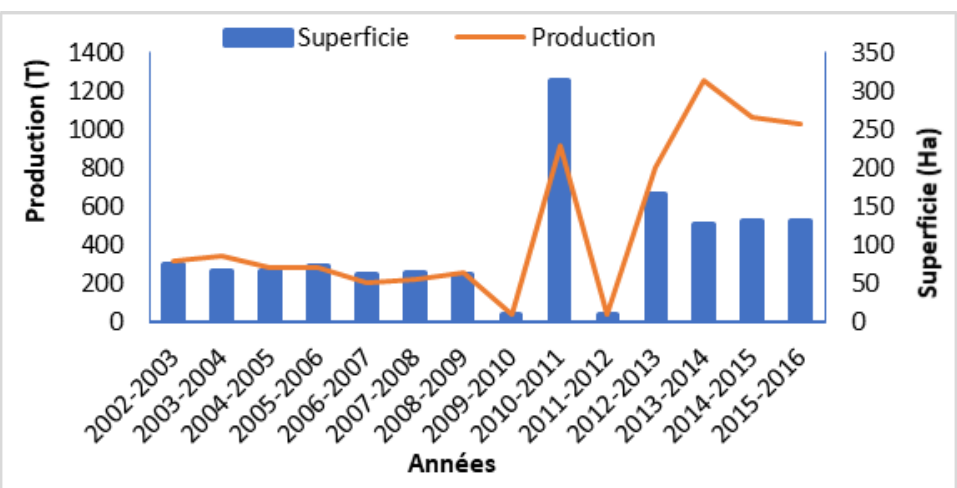

Figure 5: Evolution of Lycopersicum esculentum plantings and production from 2002 to 2016 Source : ATDA/Agbangnizoun

The analysis in Figure 5 shows that, from 2002 to 2012, the curve of Lycopersicum esculentum planting and production shows a jagged trend and follows the same pace at which the highest area sown is recorded during the 2010 and 2011 marketing years. From 2012 to 2016, production increased significantly. This situation is due to the new techniques introduced in this district. Figure 6 shows the evolution of capsicum annum plantings and production between 2002 and 2016.

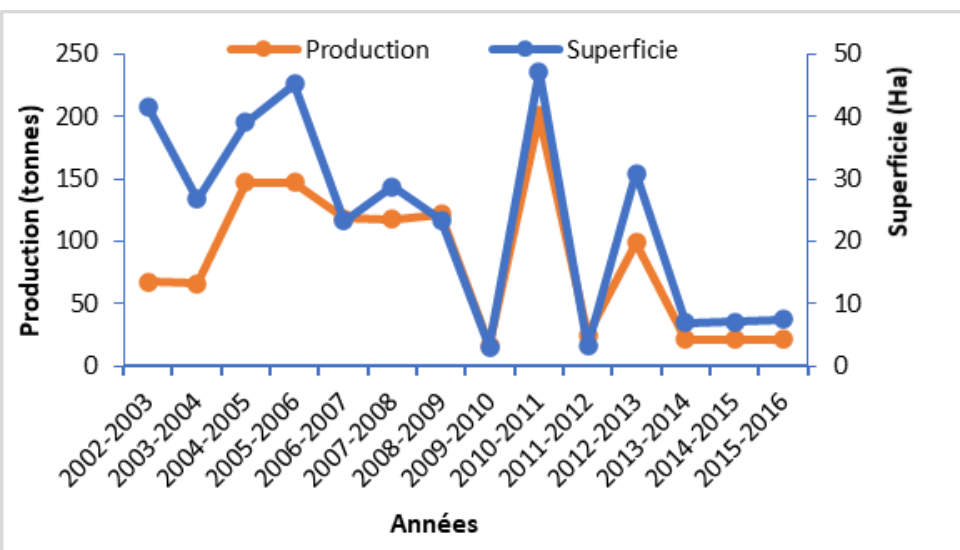

Figure 8: Evolution of capsicum annum plantings and production from 2002 to 2016 Source : ATDA/Agbangnizoun

\subsection{Wildlife regression}

According to the water and forest service, the Kinta Borough was very rich in wildlife species. Today, these species are in decline. This situation is mainly due to the method of preparation related to the practices of itinerant slash-and-burn cultivation and the demographic growth that contributes to the destruction of protected areas that can shelter these species. The wealth of the District of Kinta in Aulacode (Thryonomys swinderianus) for example has decreased considerably in recent years according to information provided by the agents of the water and forest service of the Commune.

\subsection{Impact of chemical use on soil, water and the environment}

The unprofitability of some soils and the cultivation of Zea mays and Lycopersicum esculentum have forced $60 \%$ of farmers to use chemical fertilizers such as NPK, urea, KCR, TSF. These 
fertilizers, which normally have to be used according to a given dosage, are unfortunately used in an exaggerated way because of a lack of framing.

The use of pesticide-related plant protection products allows Zea mays growers to protect plants from certain pests such as mealybugs and birds

\subsection{Socio-economic impacts}

Environmental degradation and declining agricultural productivity have serious socio-economic consequences.

Indeed, $70 \%$ of respondents say that the high mortality rate recorded in recent years in the villages of Wèdjè and Danli is due to cholera diseases, lung cancer. This situation is linked to the toxic odours of plant protection products and the pollution of water by residues from chemical fertilizers. Faced with the increasing harmful impacts of agricultural practices on the kinta Borough environment, several strategies are being developed to limit environmental risks.

The Leopold Matrix (1971) for identification, environmental impact assessment is presented in Table III.

Table III : Component of the Leopold Matrix (1971) for the identification/assessment of environmental impacts.

\begin{tabular}{|c|c|c|c|c|c|c|c|c|c|c|}
\hline \multirow{4}{*}{$\begin{array}{l}\text { Pratiques } \\
\text { agricoles }\end{array}$} & \multicolumn{10}{|c|}{ Composantes environnementales affectées par les systèmes culturaux } \\
\hline & \multicolumn{6}{|c|}{ Milieu physique } & \multicolumn{2}{|c|}{ Milieu biologique } & \multicolumn{2}{|c|}{ Milieu humain } \\
\hline & \multicolumn{3}{|c|}{ Sol } & \multicolumn{2}{|c|}{ Eau } & \multirow{2}{*}{$\begin{array}{c}\text { Air } \\
\text { Qualité }\end{array}$} & \multirow{2}{*}{$\begin{array}{c}\text { Faune } \\
\text { Animaux }\end{array}$} & \multirow{2}{*}{$\begin{array}{c}\text { Flore } \\
\begin{array}{c}\text { Couverture } \\
\text { végétale }\end{array}\end{array}$} & \multirow{2}{*}{$\begin{array}{c}\text { Social } \\
\text { Santé des } \\
\text { populations }\end{array}$} & \multirow{2}{*}{$\begin{array}{c}\text { Economic } \\
\text { ue } \\
\text { Revenus } \\
\text { par } \\
\text { paysans }\end{array}$} \\
\hline & Erosion & Acidité & Salinité & Nature & Qualité & & & & & \\
\hline $\begin{array}{c}\text { Défrichement et } \\
\text { incinération }\end{array}$ & - & - & - & - & - & - & - & - & - & + \\
\hline $\begin{array}{c}\text { Labour/billonnage/ } \\
\text { buttage }\end{array}$ & $+/-$ & $+/-$ & $+/-$ & - & - & - & - & $+/-$ & $+/-$ & + \\
\hline $\begin{array}{c}\text { Culture itinérante } \\
\text { sur brûlis }\end{array}$ & - & - & - & - & - & - & - & - & - & + \\
\hline $\begin{array}{l}\text { Usage d'engrais } \\
\text { Chimiques }\end{array}$ & - & - & - & - & - & - & - & - & - & + \\
\hline $\begin{array}{c}\text { Usage des résidus } \\
\text { agricoles et de } \\
\text { fientes } \\
\text { d'animaux } \\
\end{array}$ & $+/-$ & $+/-$ & $+/-$ & $+/-$ & $+/-$ & $+/-$ & $+/-$ & $+/-$ & $+/-$ & + \\
\hline Feu de végétation & - & - & - & - & - & - & - & - & - & + \\
\hline $\begin{array}{c}\text { Extension des } \\
\text { surfaces } \\
\text { emblavées }\end{array}$ & $+/-$ & $+/-$ & $+/-$ & $+/-$ & $+/-$ & $+/-$ & $+/-$ & $+/-$ & $+/-$ & + \\
\hline
\end{tabular}

Source: adapted from Wokou, 2007 and field survey November 2018

positive impact (+); negative impact (-); positive and negative impact (+/-) 
The analysis in Table III shows that practices such as land clearing, shifting slash-and-burn farming, wildland fire and the use of chemical fertilizers have negative effects on all environmental components. These practices have a higher degree of disruption than other practices. For the use of agricultural residues and animal droppings, ploughing/billonnage, these practices have more or less impacts on the environmental components. All of these practices have a positive trend on the economic income of peasants.

\subsection{Analyze endogenous strategies developed by farmers for sustainable environmental management}

The severity of the environmental effects related to agricultural systems in the Kinta Borough has now become a major concern for farmers who began by developing strategies for good farmland management. These strategies are mainly based on the adoption of new agricultural techniques for environmental protection, the promotion of the cultivation of the weight of pigeon (Cajanus cajan), reforestation, etc.

\subsection{Reinforcement strategies}

The most degrading environmental practices in Agbangnizoun include deep ploughing and the misuse of chemicals. To this end, it would be desirable to change the agricultural techniques of producers to make them adopt agricultural practices that respect environmental laws. For example, farmers must:

- think of the mulching system which consists in abandoning the root herbs on the spot without burning them; which fights against wind erosion and allows the restoration of soils by the decomposition of leaves;

- reduce the use of chemical fertilizers and pesticides by the Targeted Summer Control (LEC) method, which consists of intervening only on the crop at the precise moments when it is invaded by pests with reduced doses of insecticide and on a calendar basis.

- fight against fraudulent logging;

- sensitize farmers so that a minimum of trees are left during agricultural campaigns;

- involve farmers since the design, implementation and monitoring of ongoing awareness campaigns on the harmful effects of wildfires;

- encourage reforestation efforts.

\section{DISCUSSION}

The study by Mr. Boko (2002, p.112) found that the expansion of cotton cultivation and shifting burnt cultivation in the West and Central regions of Africa have led to negative environmental consequences: climate change, decline in biodiversity and accelerated land degradation.

F. Ayéko (2005, p. 37) indicate that agriculture in Africa and particularly in Benin is characterized by the small size of farms, the weakness of cultivation techniques, low mechanization and limited use of fertilizers; which leads to poor yields. They believe that soil fragility results from both natural conditions and cropping patterns (G. Wokou, 2009, p.51).

In Benin, environmental threats are real due to anthropogenic pressure (MEHU, 2001, p. 72). B. Attempted (2000, p. 19) has shown that man, in order to satisfy his ever-increasing food needs, acts uncontrollably on natural resources; this has the immediate consequences of the destruction of vegetation cover and soil erosion. 
Vol. 07, No. 01; 2022

ISSN: $2456-8643$

According to J. Assouni (2004, p. 38), the main source of environmental degradation is related to agriculture. For the author, the environmental impacts of cultivation techniques are reflected in the degradation and decline of vegetation cover due to the extension of planting, pollution, compaction and soil erosion. This situation has worsened due to the different adaptation strategies developed by farmers in the face of agriculture's vulnerability to climate change. These strategies include, among others, the increase in planting, the use of chemical fertilizers, phytosanitary products and sarclo-butting.

\section{CONCLUSION}

At the end of this research, it should be noted that the threats to which the environment is subject in the Borough of Kinta are related to agricultural systems. Environmental degradation is manifested by the regression of vegetation cover due to the system of shifting slash-and-burn cultivation and the development of new land. To remedy these difficulties, individual and collective awareness must lead the people of Agbangnizoun in general and Kinta in particular to change or improve agricultural systems and no longer destroy forests because trees and forests protect the soil by trapping carbon dioxide.

\section{REFERENCE}

ADAM Sikirou and BOKO Michel., 1993. Le Bénin, Edicef, Paris, 95 p.

AGBADJAGAN Jean., 2000. Water resources and agricultural development in Agonlin country. Master's Thesis in Geography, FLASH, UAC, 110 p.

ASSOUNI Jules., 2004. Agricultural production and environmental management in the Commune of Tchaourou. Master's Thesis in Geography, FLASH, UAC, 98 p.

AYEKO Francis., 2005. Dynamics of the sacred forests in the Commune of Zogbodomey. Mémoire de géographie, FLASH, UAC, 94 p.

BOKO Michel., 2002. Méthodes et techniques des sciences environnementales, CIFRED, Editions provisoires, Cotonou, Bénin, 224 p.

BOKO Michel., 2005. Sustainable agriculture and management of natural resources. Training module Cotonou $224 \mathrm{p}$.

BOKO Michel and OGOUWALE Euloge., 2007. Elements of methodological approach in Geography and Environmental Sciences and structure of writing study and research work, LECRJEDE, UAC, $104 \mathrm{p}$.

BONOU Grégoire., 2004. Socio-health impact of wetland farming in southern Benin: The case of the Kpanroun and Zinvié arrondissements. Master's thesis, DGAT/FLASH/UAC, 89 p.CIRAD 2010. Study of the fertility of the soils of Wallis and Futuna, n65, 26 p.

CHRIS Reijt., 2006. Traditional techniques and conservation of water and soil in Africa, CTA, CDES-Karthala, Paris, 351p.

DANSI Jean-Marie., 2007. Vegetable production in the Urban District of Lokossa: Social and environmental effect. Master's Thesis in Geography, FLASH/UAC, 68 p. 
Vol. 07, No. 01; 2022

ISSN: $2456-8643$

DANSOU Gbagou., 2011. Environmental impacts of pig farming in the Commune of Adjarra, Mémoire de géographie, UAC, 68 p.

MEHU (2001): Benin Environmental Action Plan (EAP): Interim document. Cotonou, Benin, $170 \mathrm{p}$.

TENTE Brice, 2000. Current dynamics of land use in the Atacora massif: Perma-Toucountouna sector. Master's thesis in geography, DGAT/ FLASH, UAC, 78 p.

WOKOU Guy, 2009. Agriculture and the environment on the Agonlin plateau: cropping systems and environmental changes. Mémoire de DEA, EDP, FLASH, UAC, 92 p. 